\title{
Surveillance of neonatal herpes in the British Isles 2004-2006
}

\section{[version 1; peer review: 1 approved with reservations, 1 not}

\section{approved]}

\author{
Pat A Tookey(D), Saboura Mahdavi, Catherine S Peckham
}

Population Policy and Practice Research and Teaching Department, UCL Great Ormond Street Institute of Child Health, University College London, 30 Guilford St, London, WC1N 1EH, UK

V1 First published: 04 Mar 2020, 9:163

https://doi.org/10.12688/f1000research.21538.1

Latest published: 04 Mar 2020, 9:163

https://doi.org/10.12688/f1000research.21538.1

\section{Abstract}

Background: Neonatal herpes simplex virus (HSV) infection is rare but potentially devastating and can result in neonatal death or serious disability. National incidence was estimated at 1.65/100,000 live births in an earlier British Paediatric Surveillance Unit (BPSU) study of births 1986-1991.

Methods: A second surveillance study of neonatal HSV was undertaken through the BPSU 2004-2006, with follow-up information collected on surviving children in early childhood.

Results: Over the three-year period, 85 infants were reported with confirmed neonatal HSV, an estimated incidence of 3.58/100,000 live births (95\% CI 2.86-4.42), about double that reported almost two decades earlier. Over $40 \%$ of infants were pre-term compared with $25 \%$ in the earlier period. Just over $70 \%$ had central nervous system (CNS) or disseminated infection, and among these $54 \%$ had no skin, eye or mouth lesions noted. Almost all received antivirals, but 22 (26\%) neonates died, all with disseminated or CNS infection. All but six infections were typed, of which 57\% involved HSV-2; the increased risk of adverse outcomes associated with HSV-2 in the earlier study was confirmed and strengthened, with twice as many deaths or long term disability in infants with HSV-2 than HSV-1. As before, a reported history or diagnosis of maternal HSV infection was rare prior to infant diagnosis. Likely timing of infant exposure to HSV could only be assigned in $43 \%$ of cases, of which just over half were probable postnatal transmissions.

Conclusions: Neonatal HSV infection remains rare although incidence doubled in the British Isles between the late 1990s and the mid-2000s. These findings suggest that future research should explore the relationship between pre-term delivery and infant susceptibility, and also the role of postnatal acquisition of infection. Healthcare professionals and new parents must continue to be aware of this rare condition in order to enable prompt investigation and instigation of

Open Peer Review
Approval Status
version 1
04 Mar 2020
1. Joan L Robinson
Edmonton, Canada
2. Justin C Konje, University of Leicester,
Leicester, UK
any reports and responses or comments on the
article can be found at the end of the article.


treatment.

Keywords

Neonatal Herpes, HSV, surveillance, neonates

sIJal.

This article is included in the UCL Child Health

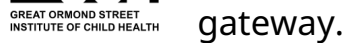

Corresponding author: Pat A Tookey (p.tookey@ucl.ac.uk)

Author roles: Tookey PA: Conceptualization, Data Curation, Formal Analysis, Funding Acquisition, Investigation, Methodology, Project Administration, Supervision, Writing - Original Draft Preparation, Writing - Review \& Editing; Mahdavi S: Formal Analysis, Project Administration, Writing - Original Draft Preparation, Writing - Review \& Editing; Peckham CS: Conceptualization, Funding Acquisition, Methodology, Writing - Original Draft Preparation, Writing - Review \& Editing

Competing interests: No competing interests were disclosed.

Grant information: The National Screening Committee provided financial support by paying the BPSU fee for inclusion. The work was undertaken at the UCL Institute of Child Health, University College London, and incidental costs were met by the Centre for Paediatric Epidemiology and Biostatistics.

The funders had no role in study design, data collection and analysis, decision to publish, or preparation of the manuscript.

Copyright: @ 2020 Tookey PA et al. This is an open access article distributed under the terms of the Creative Commons Attribution License, which permits unrestricted use, distribution, and reproduction in any medium, provided the original work is properly cited.

How to cite this article: Tookey PA, Mahdavi S and Peckham CS. Surveillance of neonatal herpes in the British Isles $2004-2006$ [version 1; peer review: 1 approved with reservations, 1 not approved] F1000Research 2020, 9:163 https://doi.org/10.12688/f1000research.21538.1

First published: 04 Mar 2020, 9:163 https://doi.org/10.12688/f1000research.21538.1 


\section{Introduction}

Neonatal herpes simplex virus (HSV) infection is a rare but potentially devastating condition which can follow primary or recurrent maternal infection in pregnancy or be acquired postnatally through direct contact with infected secretions. Transplacental transmission is unusual, and perinatal infection is usually acquired through an infected birth canal ${ }^{1,2}$.

The incidence of neonatal HSV infection ranges from about 10 per 100,000 live births in the $\mathrm{USA}^{3}$ to $2-6$ per 100,000 in the $\mathrm{UK}^{4}$, Australia $^{5}$ and Canada $^{6}$. Maternal infection close to term increases the risk of neonatal infection, and infants whose mothers have primary infection close to delivery are more likely to acquire infection than those whose mothers have recurrent infection ${ }^{7}$.

Although oral infection is predominantly associated with HSV-1, and genital infection with HSV-2, there is considerable crossover $^{8}$. Reactivation appears to be more frequent following $\mathrm{HSV}-2$ than HSV-1. Prior HSV-1 infection is partially protective against the acquisition of HSV-2 and may prevent the severe clinical manifestations associated with primary infection. Many women who have had genital HSV would not be aware of it, as both primary infection and reactivation can be asymptomatic ${ }^{9}$.

Surveillance of neonatal HSV was first undertaken through the British Paediatric Surveillance Unit (BPSU) in 1986-1991; estimated incidence of infection was then 1.65/100,000. Neonatal infection was attributed to HSV-1 and HSV-2 in equal proportion, but the virus could not be typed in one third of cases; more than half of the 76 infants reported died, or had substantial disability at follow up ${ }^{4}$.

In the light of the increasing prevalence of sexually transmitted diseases and demographic and social changes within the British population, a second BPSU study was carried out 2004-2006, with preliminary results presented in BPSU Annual Reports $^{10}$ but not elsewhere. To enable comparison over time, and with a third study being instigated through the BPSU, we want to make the final data from the second study more widely available, and highlight the changes occurring in the 20 years between the two completed national studies.

\section{Methods}

\section{Ethical statement}

Ethics approval for this study was granted by London MREC (reference MREC/03/2/80; PIAG/BPSU 2-10(g)/2005). Cases were notified through the normal BPSU protocols to this study between 2004 and 2006; paediatricians were not required to request patient consent for reporting, cases were pseudonomysed, and the study team had no contact with reported cases.

\section{Data collection}

This study was carried out through the BPSU's active national surveillance scheme, established in 1986, whereby consultant paediatricians (mainly members of the Royal College of Paediatrics and Child Health) report specified rare paediatric conditions on a monthly basis. On receipt of a report the BPSU notifies the appropriate study investigator who contacts the reporting clinician for further details. Respondents make a nil return if they have no cases to report; the BPSU monitors response rates, which at the time of this study were $94 \%$. Full details of the BPSU methodology have been described elsewhere ${ }^{11}$. For this study, paediatricians were asked to report any infant under one month of age with a laboratory-confirmed diagnosis of HSV infection, or any such infant treated with antiviral drugs for suspected HSV infection, or any stillborn infant in whom HSV was suspected, born between 1 January 2004 and 31 December 2006. Respondents were then asked to complete a standard questionnaire providing demographic, clinical and laboratory details including maternal and perinatal information, presentation and treatment. Subsequently, the notifying paediatrician was asked to provide brief follow-up information on the health outcome of the surviving children, including any further treatment required, in their second or third year of life. All clinical and laboratory investigations were undertaken locally as part of the normal care of the infant.

\section{Case definition}

Infants with neonatal HSV confirmed by virus culture, polymerase chain reaction (PCR) or immunofluorescence (IF) on a sample taken within 28 days of birth, were classified as confirmed cases. HSV type was reported by the notifying paediatrician on the basis of laboratory results.

Paediatricians were asked to classify infant presentation as disease localised to the skin, eye and/or mouth (SEM), disseminated infection, with or without central nervous system (CNS) and/or SEM involvement, or CNS infection with or without SEM involvement, as described by Whitley ${ }^{1}$, and in accord with other similar studies ${ }^{4-6}$.

Adverse health outcomes among survivors were classified as mild, moderate or severe, based on the latest clinical findings reported to the study.

\section{Data analysis}

Data were managed in a study-specific Microsoft Access 2002 database (Microsoft Corp., Redmond, Washington, USA) and were analysed using Access and Excel.

\section{Results}

Overall, 194 reports of neonatal herpes were received, and 85 infants were classified as confirmed cases of neonatal HSV.

Of these, 99 reports were excluded: 53 were duplicates and 46 did not meet the case definition; the latter category included 25 infants treated with acyclovir and reported as suspected cases, but subsequently determined, on the basis of laboratory findings, not to have neonatal HSV. The remaining 10 reports could not be classified as confirmed or excluded as no clinical or laboratory information was provided after the initial case report. This paper focuses on the 85 confirmed cases of neonatal HSV. 


\section{Confirmed neonatal cases}

A total of 45 boys and 40 girls, including two twin pairs, were reported with confirmed neonatal HSV over the three years. Seventy-one infants were born in England, nine in Scotland, and the remaining five in Wales, Northern Ireland or Ireland, giving a minimum estimated incidence of $3.58 / 100,000$ live births (95\% CI 2.86-4.42) in the British Isles. In almost all cases (79, 93\%), the virus was typed: $34(43 \%)$ HSV-1, and $42(53 \%)$ HSV-2, with another three infants (4\%) reported with dual infection (grouped with those with HSV-2 in this report).

\section{Maternal and birth factors}

Table 1 shows maternal and infant characteristics. Median maternal age at delivery was 25 years (range 15-45), and only $5 \%$ of mothers were reported to be of black or minority ethnic origin. Two sets of twins were delivered vaginally, at 32 and

Table 1. Characteristics of $\mathbf{8 3}$ women and their $\mathbf{8 5}$ infants.

\begin{tabular}{|c|c|}
\hline Maternal age at delivery ( $71 / 83$ women) & $\mathbf{N}(\%)$ \\
\hline$<20$ years & $14(20)$ \\
\hline 20-24 years & $18(25)$ \\
\hline $25-29$ years & $13(18)$ \\
\hline 30-34 years & $14(20)$ \\
\hline 35 years + & $12(17)$ \\
\hline \multicolumn{2}{|l|}{ Ethnicity (80/83 women) } \\
\hline White & $76(95)$ \\
\hline Black and minority ethnic & $4(5)$ \\
\hline \multicolumn{2}{|l|}{ Previous live births (72/83 women) } \\
\hline None & $40(56)$ \\
\hline One & $18(25)$ \\
\hline More than one & $14(19)$ \\
\hline \multicolumn{2}{|l|}{ Mode of delivery (singletons $80 / 81$ ) } \\
\hline Vaginal delivery & $52(65)$ \\
\hline Elective caesarean section & $2(3)$ \\
\hline Emergency caesarean section & $26(32)$ \\
\hline \multicolumn{2}{|l|}{ Gestational age, weeks (singletons $80 / 81$ ) } \\
\hline$>36$ weeks & $46(58)$ \\
\hline 32-36 weeks & $22(27)$ \\
\hline$<32$ weeks & $12(15)$ \\
\hline \multicolumn{2}{|l|}{ Birthweight (singletons $73 / 81$ ) } \\
\hline 2500 grams and more & $42(58)$ \\
\hline 1500-2499 grams & $22(30)$ \\
\hline$<1500$ grams & $9(12)$ \\
\hline \multicolumn{2}{|l|}{ Likely exposure (83 pregnancies) } \\
\hline Insufficient information & $47(57)$ \\
\hline Probably maternal genital HSV & $17(20)$ \\
\hline Probable postnatal exposure & $19(23)$ \\
\hline
\end{tabular}

34 weeks gestation. Just over a third of singletons (35\%) were delivered by caesarean section, but in no case was this because of concerns about herpes infection in pregnancy. Median gestational age was 38.5 weeks (range 26-42); $42 \%$ of singletons were pre-term ( $<37$ weeks). Median singleton birthweight was 2755 grams (range 948-4700) and all term infants weighed at least 2500 grams at delivery, apart from one born at 37 weeks gestation.

\section{Clinical presentation}

As shown in Table 2, 61\% (52/85) of infants presented with SEM lesions, and for 24 , this was the sole manifestation. Of the 61 infants with disseminated or CNS infection, 54\% (33) had no SEM lesions reported. Infants with HSV-1 were more likely to have SEM lesions than those with HSV-2 infection $(25 / 34,74 \% ; 23 / 45,51 \%)$; CNS and disseminated infection were more common in infants with HSV-2 infection (36/45, $80 \% ; 19 / 34,56 \%)$

\section{Treatment}

Most infants $(82 / 85,96 \%)$ were treated with acyclovir. Two of the three untreated infants died in the second week of life, and were only diagnosed at post-mortem with disseminated infection; the third, with localised infection only, was reported well at age 30 months. Two infants started treatment prior to presentation with clinical symptoms because their mothers were known to have had genital herpes infection in pregnancy (one diagnosed before delivery, one just after); another 23 were treated on the day of presentation with symptoms. The remaining 57 infants started treatment a median two days after presenting with clinical symptoms, 95\% within six days. Two infants started treatment more than two weeks after the onset of reported clinical symptoms despite having SEM involvement, but neither had any problems reported at the last follow up. Among the 63 infants who survived the neonatal period, median duration of the initial course of treatment was 14 days, and $45 \%$ received subsequent courses of treatment.

\section{Outcome}

It is known that 23 children $(27 \%)$ have died, all but one in the neonatal period (Table 3 and Figure 1); all of those who died had disseminated or CNS infection, only five also had SEM lesions, and $45 \%$ were pre-term. Of neonates with HSV-2,

Table 2. Clinical manifestation and virus type.

\begin{tabular}{|l|c|c|c|c|}
\hline & HSV-1 & HSV-2 & Virus type NK & Total \\
\hline SEM only (localised) & 15 & 9 & 0 & $\mathbf{2 4}$ \\
\hline Disseminated with SEM & 7 & 6 & 3 & $\mathbf{1 6}$ \\
\hline Disseminated no SEM & 6 & 14 & 1 & $\mathbf{2 1}$ \\
\hline CNS with SEM & 3 & 8 & 1 & $\mathbf{1 2}$ \\
\hline CNS no SEM & 3 & 8 & 1 & $\mathbf{1 2}$ \\
\hline Total & $\mathbf{3 4}$ & $\mathbf{4 5}$ & $\mathbf{6}$ & $\mathbf{8 5}$ \\
\hline
\end{tabular}

HSV, herpes simplex virus; NK, not known; SEM, skin, eye and/or mouth; CNS, central nervous system. 
Table 3. Virus type, clinical manifestation and outcome.

\begin{tabular}{|c|c|c|c|c|c|}
\hline & $\begin{array}{l}\text { Neonatal } \\
\text { death }\end{array}$ & Sequelae & $\begin{array}{c}\text { No } \\
\text { sequelae }\end{array}$ & $\begin{array}{l}\text { Lost to follow-up } \\
\text { at }<12 \text { months }\end{array}$ & Total \\
\hline \multicolumn{6}{|l|}{ Virus type } \\
\hline HSV-1 & 6 & 4 & 17 & $7^{\wedge}$ & 34 \\
\hline HSV-2 & 14 & $13^{*}$ & 12 & $6^{\wedge}$ & 45 \\
\hline Type NK & 2 & 2 & 2 & 0 & 6 \\
\hline \multicolumn{6}{|l|}{ Clinical manifestation } \\
\hline Localised & 0 & 4 & 13 & $7^{\wedge}$ & 24 \\
\hline Disseminated & 20 & 4 & 10 & $3^{\wedge}$ & 37 \\
\hline CNS & 2 & $11^{*}$ & 8 & 3 & 24 \\
\hline Total & 22 & 19 & 31 & 13 & 85 \\
\hline
\end{tabular}

* Includes one postneonatal death.

$\wedge$ Cell includes infant with developmental delay (see Figure 1).

HSV, herpes simplex virus; NK, not known; CNS, central nervous system.

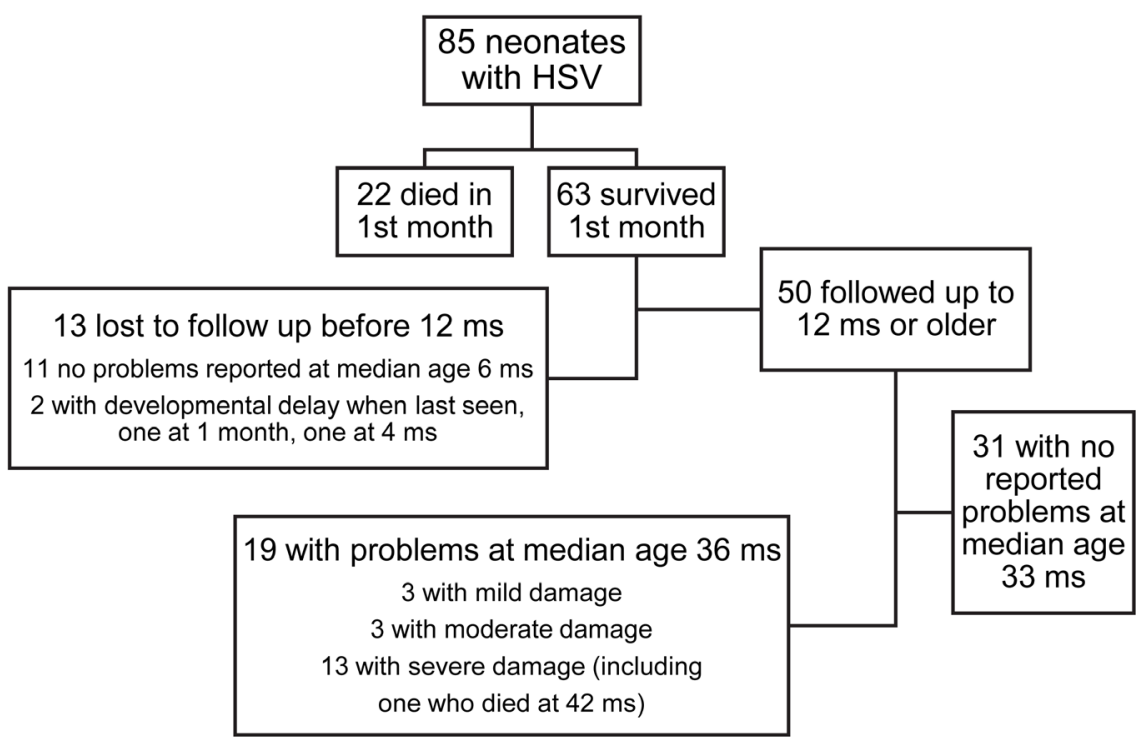

Figure 1. Flow chart. HSV, herpes simplex virus; ms, months.

$15(33 \%)$ of 45 died and six (18\%) of 34 with HSV-1 (HSV type unknown for two). Two previously asymptomatic infants who died unexpectedly in their second week of life were diagnosed with disseminated HSV-1 infection at post-mortem; the other 20 neonates who died started treatment a median of one day after presentation with symptoms, $95 \%$ within five days; all but one died within 15 days of birth.

Of the 63 survivors, $13(21 \%)$ were lost to follow up before their first birthday at a median age of five months: two showed signs of developmental delay when last seen at the ages of one and four months; the remaining 11 had no problems reported at last follow up (Figure 1).
Follow-up information was provided for the remaining 50 children at a median age of 34 months (range 12-65 months). Long-term sequelae were reported in $2 / 4$ surviving children whose virus was not typed, 4/21 (19\%) children with HSV-1 infection, and $13 / 25$ (52\%) of those with HSV-2. Severe developmental delay and major health problems including recurrent seizures, visual impairment, and quadriplegia or hemiplegia (median age at follow up 37 months, range 24-65) were reported in 13 children, including one child who died aged three years. Another six children had less severe problems reported, including speech and language delay, mild developmental delay and/or visual or hearing impairment (at median age 33 months, range 28-57). The remaining 31 children were 
reported well or with only minor health issues (at median 33 months, range 12-62).

\section{Likely source of infection}

For 48 infants (including a pair of twins), it was not possible to determine timing of exposure to HSV, that is, whether they had been exposed prenatally or around the time of delivery to maternal genital infection, or postnatally to an oral cold sore or whitlow. For the other 37 infants, 18 (including a pair of twins) were probably exposed to pre/perinatal maternal genital infection, and 19 to a probable postnatal source (Table 1).

Among the infants with probable pre/perinatal exposure, the risk was only identified prior to delivery in two cases: one woman, diagnosed with genital HSV during pregnancy, was treated with acyclovir for seven weeks between diagnosis and delivery by emergency caesarean section when she went into early pre-term labour. Another pregnant woman had reported a past history of genital HSV; following a pre-term vaginal delivery her baby was diagnosed with neonatal HSV and subsequently the mother was found to be shedding virus in the genital tract. Two more mothers reported a history of genital herpes prior to pregnancy after their babies were diagnosed. Another thirteen women were retrospectively found to have had symptoms compatible with current or recent genital HSV, including two with partners who were also diagnosed with genital infection.

In 19 cases, a parent or relative was reported to have a 'cold sore' or similar lesion around the time of delivery or infant diagnosis, or to have frequent oral cold sores; this comprised six mothers or fathers with non-genital HSV lesions, five parents who reported that they frequently had oral cold sores, and eight symptomatic visiting relatives.

Among the 35 infants with type of HSV known and a likely source of infection identified, it was more likely to be postnatal exposure $(11 / 18,61 \%)$ for infants with HSV-1 than for infants with HSV-2 (7/17, 41\%). Median gestation was 39 weeks (range 27-42) for infants probably exposed to postnatal infection; 38 weeks (26-42) for infants whose likely exposure was unknown, and 34.5 weeks (27-41) for those with likely pre/perinatal exposure.

\section{Discussion}

Although reported incidence of neonatal HSV was double that reported in the first BPSU study (3.58 v 1.65 per 100,000, 95\% CI 2.9-4.4 v 1.3-2.0) carried out almost two decades earlier ${ }^{4}$, it remained at a very low level and similar to estimates from the Australian and Canadian Paediatric Surveillance Units $^{5,6}$. Improvements in diagnostic techniques and clinical awareness may have had an impact on the reported incidence. Although the BPSU is an active reporting system with a high response rate, our estimate can only be a minimum: it is likely that there is an element of under-reporting to this national scheme; in addition, in the later study there were 10 reports of infants with insufficient information to confirm or exclude the diagnosis. However, since the methodology in the first and second BPSU studies was the same, changes over time are likely to be real. Our estimate is also considerably lower than that reported by Batra et al. for the period 2006-2012, based on an urban single centre population in England (17.5 per 100,000, 95\% CI 8.4-32.1 $)^{12}$. This could reflect differences in study methodologies, the population under review, or a further increase over time.

It was encouraging that most infections could be characterised as HSV-1 or HSV-2, in contrast to the earlier BPSU study when around a third could not be typed. Most infants were diagnosed in time to receive antiviral treatment (only three were not treated at all) unlike the earlier study where $20 \%$ of infants received no antivirals. There was also only one postneonatal death reported, compared with seven $(9 \%)$ previously with a similar length of follow up. The observation from the earlier study that a higher risk of adverse outcome is associated with HSV-2 was confirmed and strengthened, with death or long-term morbidity almost twice as common in those with HSV-2 infection as in those with HSV-1. Nonetheless, the overall proportion of adverse outcomes was lower than in the earlier study (overall $51 \%$ compared with $58 \%$ ).

A major difference between this study and the earlier one was the increase in the proportion of pre-term births - over $40 \%$ compared with $25 \%$. In this respect our findings concur with those of Batra et $a{ }^{12}$. It is possible that pre-term infants are at increased risk of acquiring HSV following perinatal exposure to primary or recurrent maternal infection, due to lack of adequate transfer of maternal antibodies at this stage of gestation $^{13-15}$. This is an issue which requires further exploration.

Although it was not possible to assign a likely source of infection in about $60 \%$ of cases, there were notable differences between the infants with probable postnatally acquired infection, who tended to be of normal gestation and more likely to have HSV-1 and SEM involvement, and those with probable pre/perinatal exposure, who tended to be born earlier and to have HSV-2. As with the previous study, a history of past infection or diagnosis prior to delivery was extremely rare, and maternal infection was generally only identified after diagnosis in the infant.

Future investigations of the national picture with respect to this rare but devastating condition should consider the role of postnatal acquisition and virus type, and the relationship between pre-term delivery and neonatal HSV following both primary and recurrent maternal genital infection. The introduction of screening for HSV susceptibility in pregnancy would not address the issue of infection in pre-term babies exposed to recurrent infection, in view of the lack of transfer of maternal antibody. The important contribution of postnatal acquisition must not be ignored or minimised in the debate around pregnancy screening. The assumption that neonatal herpes is mainly due to maternal genital infection must be challenged in this study almost a quarter of all cases, and about half of those where a likely source was identified, were attributable to postnatal exposure to cold sores and other herpetic lesions. 
These findings underline the importance of continuing awareness of this rare condition, both among healthcare staff and new parents, with prompt investigation and instigation of treatment.

\section{Data availability}

Underlying data

The data for this study was collected 2004-2006. At that time, approval to share raw individual patient data was not required or requested. Identifiers including maternal and infant dates of birth and other demographic characteristics were collected as essential study data and adequate anonymisation of data is not possible due to the rarity of the disease. Assurances were provided that all data would be kept securely and not shared outside the study team. Under these circumstances, data cannot be made publicly available, even in an anonymised form. If researchers wish to access these data for the purposes of further research, they may contact the corresponding study author, Dr Pat Tookey, by email (p.tookey@ucl.ac.uk), providing details of the information required and the intended use of the data, for example comparison with other similar case series, and we will do our best to facilitate this.

\section{Acknowledgements}

We thank the British Paediatric Surveillance Unit (BPSU), supported by the Department of Health, for facilitating the data collection, and acknowledge the invaluable contribution of the reporting clinicians. Dr David Brown (Health Protection Agency) and Richard Lynn (British Paediatric Surveillance Unit) contributed to the design of the study, and Janet Masters (d.2012) worked on data collection and data management. Any views expressed in this paper are those of the authors.
1. Whitley R: Neonatal herpes simplex virus infections. J Med Virol. 1993; 41(Suppl 1): 13-21.

PubMed Abstract | Publisher Full Text

2. Brown Z: Preventing herpes simplex virus transmission to the neonate. Herpes. 2004; 11(Suppl 3): 175A-86A. PubMed Abstract

3. Flagg $\mathrm{EW}$, Weinstock $\mathrm{H}$ : Incidence of neonatal herpes simplex virus infections in the United States, 2006. Pediatrics. 2011; 127(1): e1-8. PubMed Abstract | Publisher Full Text

4. Tookey P, Peckham CS: Neonatal herpes simplex virus infection in the British Isles. Paediatr Perinat Epidemiol. 1996; 10(4): 432-42. PubMed Abstract | Publisher Full Text

5. Jones CA, Raynes-Greenow C, Isaacs D, et al:: Population-based surveillance of neonatal herpes simplex virus infection in Australia, 1997-2011. Clin Infect Dis. 2014; 59(4): 525-31.

PubMed Abstract | Publisher Full Text

6. Kropp RY, Wong T, Cormier L, et al:: Neonatal herpes simplex virus infections in Canada: results of a 3-year national prospective study. Pediatrics. 2006; 117(6): 1955-62.

PubMed Abstract | Publisher Full Text

7. Brown ZA, Wald A, Morrow RA, et al:: Effect of serologic status and cesarean delivery on transmission rates of herpes simplex virus from mother to infant. JAMA. 2003; 289(2): 203-09.

PubMed Abstract | Publisher Full Text

8. Scoular A, Norrie J, Gillespie G, et al.: Longitudinal study of genital infection by herpes simplex virus type 1 in Western Scotland over 15 years. BMJ. 2002; 324(7350): 1366-67.

PubMed Abstract | Publisher Full Text | Free Full Text

9. Brugha R, Keersmaekers K, Renton A, et al:: Genital herpes infection: a review. Int J Epidemiol. 1997; 26(4): 698-709.

PubMed Abstract | Publisher Full Text

10. British Paediatric Surveillance Unit. 21st Annual Report 2006-2007. 2007.

11. Lynn R, Pebody R, Knowles R: Twenty years of active paediatric surveillance in the the UK and Republic of Ireland. Euro Surveill. 2006; 11(7): E060720.4. PubMed Abstract | Publisher Full Text

12. Batra D, Davies $P$, Manktelow $B N$, et al: The incidence and presentation of neonatal herpes in a single UK tertiary centre, 2006-2013. Arch Dis Child. 2014; 99(10): 916-21.

PubMed Abstract | Publisher Full Text

13. Prober CG, Sollender WM, Yasukawa LL, et al.: Low risk of herpes simplex virus infections in neonates exposed to the virus at the time of vaginal delivery to mothers with recurrent genital herpes simplex virus infections. N Engl J Med. 1987; 316(5): 240-44. PubMed Abstract | Publisher Full Text

14. Palmeira $\mathrm{P}$, Quinello $\mathrm{C}$, Silveira-Lessa $\mathrm{AL}$, et al: IgG placental transfer in healthy and pathological pregnancies. Clin Dev Immunol. 2012; 2012: 985646. PubMed Abstract | Publisher Full Text | Free Full Text

15. Simister N: Placental transport of immunoglobulin G. Vaccine. 2003; 21(24): 3365-69.

PubMed Abstract | Publisher Full Text 


\title{
Open Peer Review
}

\section{Current Peer Review Status: $\mathrm{X}$ ?}

\section{Version 1}

Reviewer Report 25 November 2021

https://doi.org/10.5256/f1000research.23731.r98091

(C) 2021 Konje J. This is an open access peer review report distributed under the terms of the Creative Commons Attribution License, which permits unrestricted use, distribution, and reproduction in any medium, provided the original work is properly cited.

\begin{abstract}
Justin C Konje
Professor of Obstetrics and Gynaecology, Department of Health Sciences, University of Leicester, Leicester, LE1 7RH, UK

This important surveillance study for the period 2004-6 was the second in the British Isles, the first was for the period 1986-91. The key findings were an increased incidence (almost doubled that of the previous period), a higher prevalence in preterm infants and $57 \%$ secondary to HSV-2. The authors suggest that improvements in diagnostic techniques and clinical awareness may have had an impact on the reported incidence. I believe that this surveillance report adds to our continuing drive to increase not only awareness but the importance for clinicians to recognise that neonatal HSV remains an important cause of morbidity and mortality.
\end{abstract}

\section{Major Comments:}

\section{Abstract:}

1. It reads as if this was a comparative study - making repeated reference to the surveillance of 1986-1991 in the results paragraph. While this is important it should not be in the results. Reference to this is appropriate in the conclusion.

2. The comment that "the increased of adverse outcomes associated with HSV-2 in the earlier study was confirmed and strengthened" should be revised and I will suggest deleting the word "strengthened" as there is no evidence to back this up.

\section{Introduction}

1. Although prior HSV-1 offers more relative protection to HSV-2 infection, there are some studies that also show that prior HSV-2 offers some protection against HSV-1 (not to the Methods same degree) - e.g. Brown ZA et al. (1997) ${ }^{1}$; Nahmais et al. (1990) ${ }^{2}$.

1. In the case identification, reference is made to paediatricians reporting on stillbirths with confirmed HSV infection. This is unlikely to be reported by paediatricians. If this is indeed the case, then it is possible that some data would be inaccurate. Ideally this should come from the laboratory where the diagnosis is confirmed. Perhaps this should be discussed as a limitation of this approach. Furthermore, this is a survey of neonatal HSV and stillbirths 
should not be included as neonates. Furthermore, the Flow chart rightly does not include the SBs - so exclude please.

2. Provide a definition of 'mild moderate or severe disease"

\section{Results}

1. In the maternal and birth factors, there were 29 emergency CS and 2 elective CS. An important factor in vertical transmission at the time of delivery is pre-delivery rupture of membranes. Was it possible to obtain this information? This is very important with respect to understanding of how these 26 neonates acquired HSV. This is also most likely linked to the gestational age. It would be interesting to know how many of the CS were $<36$ weeks.

2. With regards to the timing of symptoms -it was not immediately clear to me whether reference to initiating treatment was also related to the onset of symptoms. Important information that would provide clues to the time of acquisition would be the time of onset of symptoms from birth. The incubation period would help identify those infections acquired at the time of delivery and those acquired after birth.

\section{Discussion}

1. Is there any evidence from the data that over the period of the surveillance, the reported incidence was increasing? If there is none, then the statement on improvements in diagnostic techniques is unlikely to have been a significant factor in the risen incidence. I agree that increased awareness on the part of clinicians is most likely to have been a major driver of the higher reported number of cases.

2. At the end of the third paragraph the authors state that the increased incidence in preterm babies may be because of lack of adequate transfer of antibodies following perinatal exposure to primary or recurrent infection. I would agree with primary but not recurrent infections. I am more inclined to believe that several factors are at play - premature rupture of membranes especially preterm (which increased vertical transmission) and genital coinfections that are known to be a factor in preterm delivery - all increasing the risk of vertical transmission.

3. There is no evidence that maternal transfer of antibodies is influenced by gestational age. It is influenced by timing of infection/duration of infection prior to delivery. Please revise this statement in paragraph 5.

4. I am not sure that enough evidence is presented to challenge the fact that more neonatal HSV is acquired genitally (paragraph 5). I think the authors ought to discuss prelabour rupture of fetal membranes as a factor that increases risk and while this may not have been collected, it must be discussed as a major weakness of the study (i.e. inference on timing of infection cannot be made without this).

5. I am not sure how warning all parents would prevent cases - I would suggest that better education of clinicians (family practitioners and paediatricians) would increase case identification and institution of early treatment

Minor

1. Data are plural. 


\section{References}

1. Brown ZA, Selke S, Zeh J, Kopelman J, et al.: The acquisition of herpes simplex virus during pregnancy.N EnglJ Med. 1997; 337 (8): 509-15 PubMed Abstract | Publisher Full Text

2. Nahmias AJ, Lee FK, Beckman-Nahmias S: Sero-epidemiological and -sociological patterns of herpes simplex virus infection in the world.Scand J Infect Dis Suppl. 1990; 69: 19-36 PubMed Abstract

Is the work clearly and accurately presented and does it cite the current literature? Partly

Is the study design appropriate and is the work technically sound?

Yes

Are sufficient details of methods and analysis provided to allow replication by others? Yes

If applicable, is the statistical analysis and its interpretation appropriate?

Yes

Are all the source data underlying the results available to ensure full reproducibility? Yes

Are the conclusions drawn adequately supported by the results?

No

Competing Interests: No competing interests were disclosed.

Reviewer Expertise: 1. Fetal growth 2. Perinatal infections

I confirm that I have read this submission and believe that I have an appropriate level of expertise to confirm that it is of an acceptable scientific standard, however I have significant reservations, as outlined above.

Reviewer Report 29 July 2021

https://doi.org/10.5256/f1000research.23731.r90155

(C) 2021 Robinson J. This is an open access peer review report distributed under the terms of the Creative Commons Attribution License, which permits unrestricted use, distribution, and reproduction in any medium, provided the original work is properly cited.

Joan L Robinson

Department of Pediatrics, University of Alberta, Edmonton, Alberta, T6G 1C9, Canada

The authors prevent results from a 2004-2006 active surveillance study for neonatal HSV infection. 


\section{Major points:}

The abstract claims that there is increased severity with HSV-2 infection but does not provide data from the study to verify that.

Introduction - "Although oral infection is predominantly associated with HSV-1, and genital infection with HSV-2, there is considerable crossover." The reference provided verifies that HSV-1 commonly causes genital disease but I am not aware that there is evidence that HSV2 causes oral disease. Please provide a reference if this is the case.

Methods - It needs to be clearer which cases were included. The authors state: "For this study, paediatricians were asked to report any infant under one month of age with a laboratory-confirmed diagnosis of HSV infection, or any such infant treated with antiviral drugs for suspected HSV infection, or any stillborn infant in whom HSV was suspected, born between 1 January 2004 and 31 December 2006." However, later it sounds like all but confirmed cases were excluded. It is not clear why pediatricians were asked to report suspected cases or stillborns with possible HSV if they were going to be excluded unless they had lab confirmation.

Results: "Infants with HSV-1 were more likely to have SEM lesions than those with HSV-2 infection (25/34, 74\%; 23/45, 51\%); CNS and disseminated infection were more common in infants with HSV-2 infection (36/45, 80\%; 19/34, 56\%)." Are these differences statistically significant? If so, evidence should be provided.

Results: "Two infants started treatment more than two weeks after the onset of reported clinical symptoms despite having SEM involvement, but neither had any problems reported at the last follow up." The latter part belongs in the Outcomes section.

Results: "Among the 63 infants who survived the neonatal period, median duration of the initial course of treatment was 14 days, and $45 \%$ received subsequent courses of treatment." What was the range and IQR for duration of treatment? I was surprised that almost half were treated again. Can the authors provide more details? Were any started on acyclovir prophylaxis or was it always treatment?

The incidence of postnatal exposure is unexpectedly high. The Methods section should explain how this was determined. I disagree with the method that is outlined in the Results section. Most women with genital HSV do not have a history of genital ulcers. Most adults with cold sores do not transmit HSV-1 to a neonate. All prior studies suggested that most cases were transmitted at the time of delivery even if mother had no history of genital lesions. The fact that a visiting relative had a cold sore does not convince me that transmission was post-natal. Should the authors not looked at the day of onset of symptoms since if onset is very early, it seems unlikely transmission was post-partum? It would be exceedingly unlikely that HSV-2 was acquired from post-partum transmission, especially from a visiting relative.

Is it possible to say how many of the deaths were attributable to HSV?

Mild, moderate and severe damage need to be defined in Methods. 
How can one have a developmental delay at one month of age? An infant does not have to even smile to be normal at one month of age.

Discussion - "Future investigations of the national picture with respect to this rare but devastating condition should consider the role of postnatal acquisition and virus type, and the relationship between pre-term delivery and neonatal HSV following both primary and recurrent maternal genital infection." - This is a rather vague sentence. How will investigating the virus type and the role of preterm delivery help in the future?

Discussion - "The introduction of screening for HSV susceptibility in pregnancy would not address the issue of infection in pre-term babies exposed to recurrent infection, in view of the lack of transfer of maternal antibody." - Those who believe in identifying susceptible women advise that they practice safe sex if their partner is positive. I could not understand how this relates to preterm infants.

Discussion - "The important contribution of postnatal acquisition must not be ignored or minimized in the debate around pregnancy screening. The assumption that neonatal herpes is mainly due to maternal genital infection must be challenged - in this study almost a quarter of all cases, and about half of those where a likely source was identified, were attributable to postnatal exposure to cold sores and other herpetic lesions." As mentioned above, the authors have not convincingly shown that a large number of cases are acquired after birth.

Do the authors truly believe that warning all new parents about this rare condition is a good idea and would prevent cases?

Discussion - "Nonetheless, the overall proportion of adverse outcomes was lower than in the earlier study (overall 51\% compared with 58\%)." Here and throughout the paper, the authors should not imply that there is a difference unless it is statistically significant.

\section{Minor points:}

It would be helpful to the reader if both absolute numbers and percentages are provided in the abstract and throughout the paper.

Ethical statement - "Between 2004 and 2006" would really only be 2005 . How about "2004 through 2006"?

It is not clear why the data are being submitted for publication about a decade after the last follow-up data were collected.

\section{Is the work clearly and accurately presented and does it cite the current literature?} No

\section{Is the study design appropriate and is the work technically sound?}


Are sufficient details of methods and analysis provided to allow replication by others? No

If applicable, is the statistical analysis and its interpretation appropriate?

I cannot comment. A qualified statistician is required.

Are all the source data underlying the results available to ensure full reproducibility? No

Are the conclusions drawn adequately supported by the results? No

Competing Interests: No competing interests were disclosed.

Reviewer Expertise: Pediatric Infectious Diseases

I confirm that I have read this submission and believe that I have an appropriate level of expertise to state that I do not consider it to be of an acceptable scientific standard, for reasons outlined above.

The benefits of publishing with F1000Research:

- Your article is published within days, with no editorial bias

- You can publish traditional articles, null/negative results, case reports, data notes and more

- The peer review process is transparent and collaborative

- Your article is indexed in PubMed after passing peer review

- Dedicated customer support at every stage

For pre-submission enquiries, contact research@f1000.com

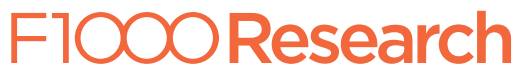

